\title{
Effect of Activated Carbons on the Dielectric and Microwave Properties of Natural Rubber Based Composites
}

\author{
Abdullah G. Al-Sehemi ${ }^{i, b}$, Ahmed A. Al-Ghamdic, Nikolay Dishovsky ${ }^{d *}$, Radostin N. Nickolove, \\ Nikolay T. Atanasov ${ }^{f, g}$, Liliya T. Manoilova ${ }^{e}$ \\ ${ }^{a}$ Research Center for Advanced Materials Science (RCAMS), King Khalid University, Abha 61413, P.O. \\ Box 9004, Saudi Arabia \\ ${ }^{b}$ Department of Chemistry, College of Science, King Khalid University, Abha 61413, P.O. Box 9004, \\ Saudi Arabia \\ ${ }^{c}$ Department of Physics, Faculty of Science, King Abdulaziz University, Jeddah, Saudi Arabia \\ ${ }^{d}$ Department of Polymer Engineering, University of Chemical Technology and Metallurgy, \\ 1756 Sofia, Bulgaria \\ ${ }^{e}$ Department of Technology of Organic Synthesis and Fuels, University of Chemical Technology and \\ Metallurgy, 1756 Sofia, Bulgaria \\ ${ }^{f}$ Department of Telecommunications, Faculty of Telecommunications and Management, University of \\ Telecommunications and Post, 1700 Sofia, Bulgaria \\ ${ }^{g}$ Department of Communication and Computer Engineering, Faculty of Engineering, South-West \\ University 'Neofit Rilski', 2400 Blagoevgrad, Bulgaria
}

Received: April 17, 2017; Accepted: June 19, 2017

The effect of six different types of activated carbons has been studied in view of their applicability as functional fillers upon the dielectric and microwave properties of natural rubber based composites. It is found that the textural characteristics of the studied active carbons exert influence both on the real part of dielectric permittivity and dielectric loss angle tangent, as well as on the microwave properties of the studied composites. The composite containing activated carbon on the basis of wooden material possesses the highest value of the total shielding effectiveness in comparison with the composites, containing another activated carbons. It has the lowest values of specific surface area, area and volume of micropores and the highest values of external surface area, volume of mesopores and average pore diameter. With gradually increasing the values of the indices in the first group and gradually decreasing the values of the indices in the second group, the value of total shielding effectiveness decreases. It is obvious that these indices have influence on the rubber matrix-filler particle interactions, such as multicontact chain adsorption to the surface of the filler. The spatial inhomogeneities formed give rise to polarization phenomena and to a frequency dependence of the dielectric properties.

Keywords: activated carbon, rubber composites, functional fillers, dielectric and microwave properties

\section{Introduction}

The production of materials possessing microwave absorbing properties has acquired significant importance recently. The most important applications of microwave absorbing composites are as follows: antenna techniques and production - improving the antenna parameters; protection of humans and other biological objects from the harmful effect of the electromagnetic waves; military application - for anti-radar camouflage, to reduce the radar cross section of objects; improving the electromagnetic compatibility between different electronic devices, reducing undesirable reflections from objects and devices; to cover the inside surface of test rooms (anechoic chambers) in order to achieve "free space" conditions for measurements of components and systems ${ }^{1,2}$.

*e-mail: dishov@uctm.edu
There has been a long history for research into carbonaceousbased microwave absorbers ${ }^{3-7}$.

Carbon (C) is the fourth most abundant chemical element in the universe by mass after hydrogen, helium, and oxygen. The inherent charge transport characteristics and the factors that limit the charge carrier mobility differ significantly between the various carbonaceous nanostructures reflecting, on the one hand, the electronic dimensionality of the structures, and, on the other hand, the achievable dimensions of the respective $\pi$-systems ${ }^{8}$.

Carbon black and graphite remained the favorite absorbing candidates until the discovery of CNTs in the 1990s, which have been exploited to a wide range of potential industrial applications, including microwave absorbers ${ }^{9-16}$. Since the beginning of this millennium, other forms of carbonaceousbased absorbers with good absorption characteristics have 
appeared. Most recently, graphene joined the carbonaceous family for microwave absorbers applications ${ }^{17-19}$.

The active carbons are defined as carbonaceous materials, possessing well developed porous texture (more often a micro- mesoporous or a meso- microporous), containing about $87-97 \%$ carbon. They are classified into the group of the so called mixed (transitional) forms of carbon, in which the atoms can participate in various combinations, corresponding to $s p^{3}$-, $s p^{2}$ - and $s p$ types of hybridization of the electron orbitals. The availability of strongly developed $\left(>100 \mathrm{~m}^{2} / \mathrm{g}\right.$ ) external surface, which usually contains considerable amount of surface oxygen-containing groups (SOG), determining the value of isoelectric points (IEP) is a prerequisite for the interaction between the macromolecules of the elastomer and the surface of the active carbon. It is well known that the interaction "elastomer-filler", determined most of all by adsorption phenomena, lie at the basis of the process of formation of the properties of elastomeric composites. On the other hand, it can be supposed that the specific structure of the active carbon will exert positive influence upon the dielectric losses. It will result in achieving a higher degree of absorbance and lower degree of reflection of the electromagnetic waves. The data published on the utilization of active carbons as reinforcing fillers are quite a few ${ }^{20}$, while such data on their use as functional fillers in elastomeric composites, absorbing the electromagnetic waves, are practically missing.

In this study, the complex dielectric constant (the real part of permittivity and dielectric loss tangent) and microwave properties (such as: reflection coefficient, attenuation coefficient, and shielding effectiveness) of rubber composites, containing activated carbons differing in their textural characteristics, were investigated within the frequency range from $1 \mathrm{GHz}$ to $12 \mathrm{GHz}$ with the aim to establish:

- the values of the textural parameters and the IEPs of the active carbons, within such range of limits, where they could be applied as fillers, without creating any technological problems during the vulcanization process;

- $\quad$ the influence of textural parameters of the activated carbon on the complex dielectric constant (the real part of permittivity and dielectric loss angle tangent) and microwave properties (such as: attenuation and reflection coefficients, the total, reflective and absorptive shielding effectiveness) of composites on the basis of natural rubber in the frequency range from $1 \mathrm{GHz}$ to $12 \mathrm{GHz}$.

\section{Experimental}

\subsection{Activated carbons}

Six types of active carbon have been used, differing in their adsorption-textural parameters. These types of active carbon are the following: Norit, AG-K, ART, AC-L, 207C and ACVM. AG-K and AC-L are based on anthracite or respectively on lignite brown coal, the Norit and ART types are on the basis of wooden material, while the $207 \mathrm{C}$ and ACVM samples have been prepared from different nuts or fruit stones, respectively from cocoa nuts apricot stones.

The carbon samples ACVM and AC-L have been prepared by us using steam-gas activation and the rest of the samples are commercial products.

\subsection{Activated carbons characterization}

The activated carbons have been characterized by means of low-temperature nitrogen adsorption (at 77.4 K) using Quantachrome Instruments NOVA 1200e (USA) apparatus.

On the basis of the adsorption-desorption equilibrium nitrogen isotherms, applying the specialized software, belonging to the apparatus, the following textural parameters have been calculated:

- $\quad$ specific surface area $\left(\mathrm{A}_{\mathrm{BET}}\right)$ after the equation of Brunauer-Emmet-Teller, for the pressure range $\mathrm{P} /$ $\mathrm{P}_{\mathrm{O}}=0.05-0.35$ (adsorbate $\mathrm{N}_{2}$, at $77.4 \mathrm{~K}$ );

- volume of the micropores $\left(\mathrm{V}_{\mathrm{MI}}\right)$ using the Density Functional Theory (DFT) (adsorbate $\mathrm{N}_{2}$, at $77.4 \mathrm{~K}$ );

- total pore volume $\left(\mathrm{V}_{\mathrm{t}}\right)$ in accordance with the Rule of Gurvich for the pressure range $\mathrm{P} / \mathrm{P}_{\mathrm{O}}=0.95$ (adsorbate $\mathrm{N}_{2}$, at $77.4 \mathrm{~K}$ );

- $\quad$ volume of the mesopores $\left(\mathrm{V}_{\mathrm{MES}}\right)$, estimated as the difference between the total pore volume and the volume of micropores (adsorbate $\mathrm{N}_{2}$, at $77.4 \mathrm{~K}$ );

- $\quad$ size distribution of the micropores based on the equation of Dubinin-Astakhov ${ }^{21}$;

- $\quad$ size distribution of the mesopores within the interval $1.7-15 \mathrm{~nm}$ on the basis of the adsorption branch of the adsorption-desorption equilibrium isotherm, using the Density Functional Theory;

- $\quad$ average pore diameter $\left(\mathrm{D}_{\mathrm{AV}}\right)$ as the ratio between $\mathrm{V}_{\mathrm{t}}$ multiplied by four and the specific surface area $\mathrm{A}_{\mathrm{BET}}$ (adsorbate $\mathrm{N}_{2}$, at $77.4 \mathrm{~K}$ );

- $\quad$ the external surface area $\left(\mathrm{A}_{\mathrm{EXT}}\right)$ based on the $\alpha_{S}$ method $^{22}$, from the adsorption branch of the isotherm (adsorbate $\mathrm{N}_{2}$, at $77.4 \mathrm{~K}$ ).

The isoelectric points (IEP) of the carbons have been determined by the method of Noh and Schwarz ${ }^{23}$. For this purpose, three different initial solutions having various $\mathrm{pH}$ factor have been prepared for each type of carbon (respectively $\mathrm{pH} 3,6$ and 11), using $\mathrm{HNO}_{3}(0.1 \mathrm{M})$ and $\mathrm{NaOH}(0.1 \mathrm{M})$. Six flasks for each type of carbon were charged with $20 \mathrm{ml}$ of the solutions and with various quantities of the studied carbon sample $(0.05 \mathrm{~g}, 0.50 \mathrm{~g}, 0.75 \mathrm{~g}, 1.00 \mathrm{~g}, 5.00 \mathrm{~g}$ and $10.00 \mathrm{~g}$ ). The equilibrated $\mathrm{pH}$ was measured after 24 hours. The curves of the dependences of the $\mathrm{pH}$ on the mass of the carbon samples are passing over to a plateau and the 
isoelectric point was determined as the value, at which the change in $\mathrm{pH}$ becomes zero.

\subsection{Sample preparation and vulcanization}

A rubber compound, taken as a reference, and six samples of different activated carbon powder of one and the same quantity were charged in an open two-roll laboratory mill (L/D 320x160 and friction 1.27). The speed of the slow roll was $25 \mathrm{~min}^{-1}$. The formulations of the prepared samples are shown in Table 1. The inclusion of sulfur (vulcanization agent), zinc oxide (activator), stearic acid (dispersing agent and accelerating activator) and TBBS (N-tert-Butyl-2benzothiazolesulfonamide-accelerator) was done with the aim to accomplish a normal vulcanization process ${ }^{24}$. The process of mixing was carried out as follows: loading some raw rubber, afterwards the zinc oxide was added on the 5 th minute as well as the stearic acid, then after 3 minutes of homogenization treatment the activated carbon powders were added, and after 7 minutes of homogenization the accelerator and the sulfur were added. Finally the mixture was again homogenized for 4 minutes. The temperature of the rolls did not exceed $70^{\circ} \mathrm{C}$. The experiments were repeated to check statistically the reproducibility. Samples in the form of sheets stayed for 24 hours prior to their vulcanization. The optimal vulcanization time interval was determined by the vulcanization isotherms taken on an oscillating disc vulcameter MDR 2000 (Alpha Technologies) at $150^{\circ} \mathrm{C}$ according to ISO 3417:2002 standard.

The rheometer was carried out in a hydraulic electric press, with the size of the plate $400 \times 400 \mathrm{~mm}$ at a pressure of 10 MPa. The obtained samples had dimensions 200x200x1.5 mm.

\subsection{Microwave properties measurement}

Figure 1 indicates the mechanism of interaction of one composite with the electromagnetic wave, possessing incident power $P_{I}$. A fraction of the power of the wave is reflected by the surface of the material $P_{R}$. Another fraction passes into the material and it is absorbed by it, being transformed into a quantity of heat $P_{A}$, and the remaining part of the power is disseminated after the sample $P_{T}$.

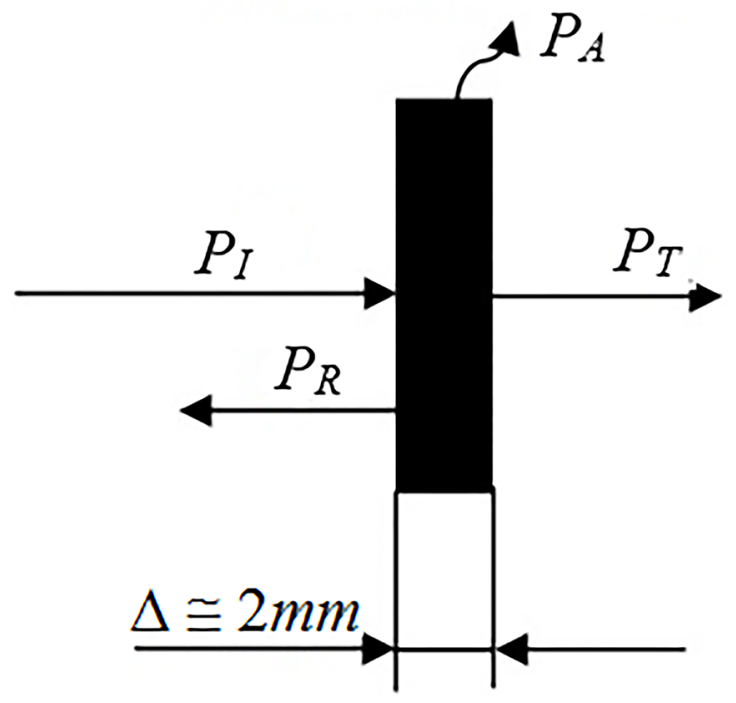

Figure 1. Mechanism of interaction of the composite with the incident power of the electromagnetic wave.

The shielding effectiveness is defined as the ratio between the power incident on the sample $P_{I}$ and the power passing through the sample $P_{T}$ in accordance with the equation $(1)^{25-27}$ :

$$
S E=10 \log \frac{P_{I}}{P_{T}}
$$

The total shielding effectiveness ( $\mathrm{SE}$, in $\mathrm{dB}$ ) and the reflective shielding effectiveness of the sample surface $\left(\mathrm{SE}_{\mathrm{R}}\right.$, in $\left.\mathrm{dB}\right)$ are determined by the equations (2) and (3) $)^{28-31}$ :

$$
S E=-10 \lg T,
$$

where $T=/ P_{T} / P_{I} /=/\left.\mathrm{S}_{21}\right|^{2}$,

$$
S E_{R}=-10 \lg (1-R),
$$

where $R=/ P_{R} / P_{I} /=/ \mathrm{S}_{11}{ }^{2}$,

$S_{1 I}$ and $S_{2 I}$ are complex scattering parameters or $S$-parameters $\left(S_{I I}\right.$ corresponds to the reflection coefficient and $S_{21}$ - to the transmission coefficient).

Table 1. Formulation of the studied NR based compounds (in parts per 100 parts of rubber).

\begin{tabular}{lccccccc}
\hline & NR1 & NR2 & NR3 & NR4 & NR5 & NR6 & NR7 \\
\hline Natural rubber SMR 10 & 100 & 100 & 100 & 100 & 100 & 100 & 100 \\
Zinc oxide & 5 & 5 & 5 & 5 & 5 & 5 & 5 \\
Stearic acid & 2 & 2 & 2 & 2 & 2 & 2 & 2 \\
Activated carbon powder & 0 & Norit & AG-K & ART & ACL & $207 C$ & ACVM \\
TBBS & 0.8 & 0.8 & 0.8 & 0.8 & 0.8 & 0.8 & 0.8 \\
Sulfur & 2.25 & 2.25 & 2.25 & 2.25 & 2.25 & 2.25 & 2.25 \\
\hline
\end{tabular}

Note: The amounts of activated carbons in samples NR2-NR7 are $70 \mathrm{phr}$. 
The absorptive shielding effectiveness $\left(S E_{A}\right)$ is calculated as the difference between (2) and (3), as it is shown in equation $(4)^{26,28-31}$ :

$$
S E_{A}=S E-S E_{R}
$$

The attenuation coefficient $(\boldsymbol{\alpha}, \boldsymbol{d B} / \mathbf{c m})$ was determined using Equation (4). Substituting $\mathrm{SE}$ and $\mathrm{SE}_{\mathrm{R}}$ in it with Equations (2) and (3), Equation (5) is obtained.

$$
S E_{A}=10 \lg \left(\frac{P_{I}\left(1-\left|S_{11}\right|^{2}\right)}{P_{r}}\right)
$$

For determining the attenuation coefficient, Equation (5) was divided by the thickness of the sample $\boldsymbol{d}$ in centimeters, as shown in Equation (6).

$$
\alpha=\frac{S E_{A}}{d}=10 \lg \left(\frac{P_{T}}{P_{I}\left(1-\left|S_{11}\right|^{2}\right)}\right)
$$

For the evaluation of the shielding effectiveness and measuring the coefficient of reflection from the surface of the studied composites the apparatus, represented in Figure 2, has been applied. It consists of coaxial reflectometric system (directed deviators Narda model 4222-16 and detectors Narda FSCM 998999 model 4503A, separating the incident power from the reflected power in the line), Ratio Meter) HP Model 416A, calculating and depicting the amplitude of the coefficient of reflection from the sample, a series of radio wave frequency generators G4-37A,G4-79 to G4-82 and $\mathrm{HP} 68 \mathrm{~A}$ in the frequency interval from $1 \mathrm{GHz}$ to $12 \mathrm{GHz}$, the signal generator BM492 releasing a modulating signal of frequency $1 \mathrm{kHz}$ directed towards the radio frequency generator, coaxial transmission line Orion type E2M for frequencies from $1 \mathrm{GHz}$ to $5 \mathrm{GHz}$ and coaxial measuring line APC-7mm for frequencies from $6 \mathrm{GHz}$ to $12 \mathrm{GHz}$, power measuring device HP 432A. The critical frequencies for the coaxial measuring lines were determined by the formulas represented in $^{32-33}$.

The radio frequency generator and the reflection-measuring system (reflectometer) are interconnected by means of rugged phase stable cable N9910X-810 Agilent and through the connectors to avoid any interference.

The measurements have been carried out observing the following procedure:

a) calibration of the system for removal of the systematic errors using the above mentioned kits of calibrating tools and the standard procedures, described in ${ }^{34-35}$.

b) Cutting out samples from the obtained vulcanized materials having dimensions as follows:

- $\quad$ external diameter of $20 \mathrm{~mm}$ and internal diameter of $7 \mathrm{~mm}$ in case of using coaxial transmission line Oreon E2M;

- $\quad$ external diameter of $7 \mathrm{~mm}$ and internal diameter of $3 \mathrm{~mm}$ in case of using coaxial measuring line APC $-7 \mathrm{~mm}$.

c) Carrying out measurements for determining the module of the coefficient of reflection using:

- $\quad$ standard load of the type Agilent 1250, connected in the position of the coaxial line;

- blank coaxial line with a standard load at the end (calibrating kit of tools of the type Agilent N9330);

- coaxial line with with inserted standard material (polytetrafluoroethylene PTFE load of thickness $1 \mathrm{~mm}$ ) for confirming the correctness of the measurements done;

d) the studied sample is placed between the external and the internal conductor of the coaxial line;

The measurements have been carried out at room temperature varying from $19^{\circ} \mathrm{C}$ up to $24^{\circ} \mathrm{C}$ and incident power $P_{I}$ at the inlet of the coaxial measuring line varying from $800 \mu \mathrm{W}$ up to $1300 \mu \mathrm{W}$ within the frequency range of $1 \mathrm{GHz}$ to $12 \mathrm{GHz}$.

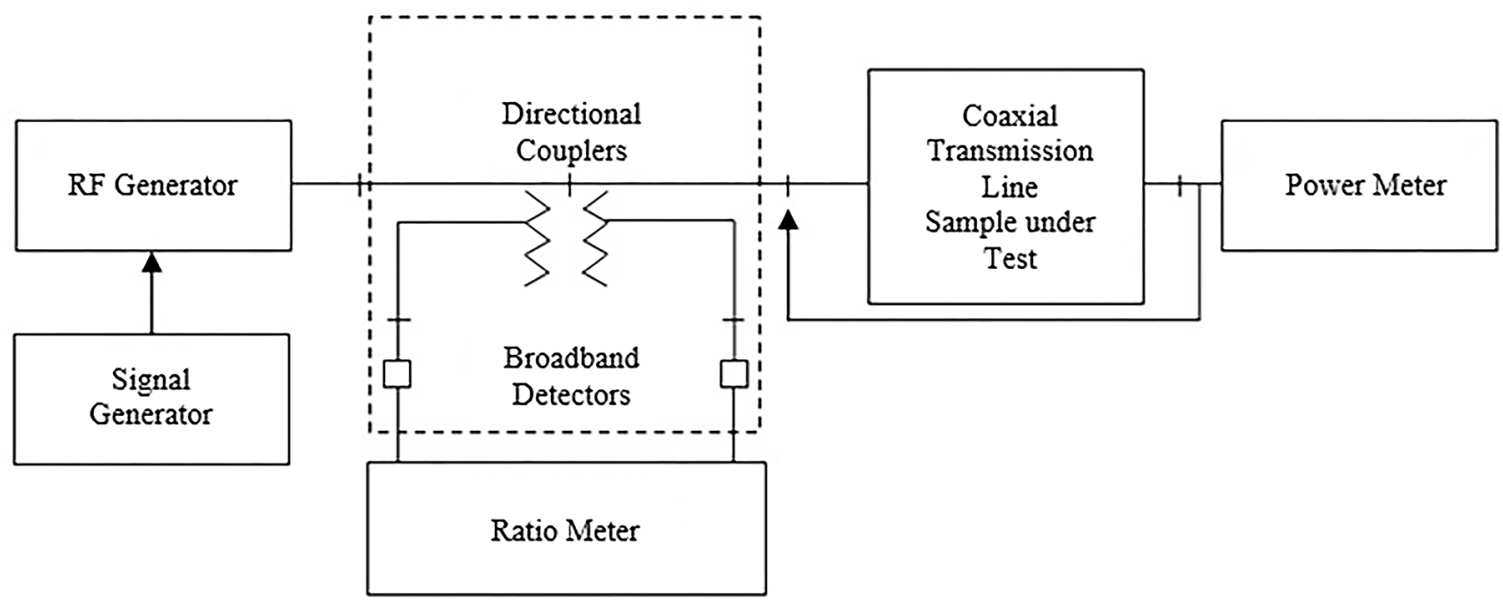

Figure 2. Apparatus for measuring the microwave properties. 


\subsection{Dielectric properties measurement}

\subsubsection{Complex permitivity}

The determination of complex permitivity has been carried out by the resonance method, based on the cavity perturbation technique. The resonance frequency of an empty cavity resonator $f_{r}$ has also been measured. After that the sample material was placed into the resonator and the shift in resonance frequency $f_{\varepsilon}$ has been measured. The real part of permittivity $\varepsilon^{\prime}$, was calculated from the shift in resonance frequency, cavity and the sample cross-sections $S_{r}$ and $S_{\varepsilon}$ respectively

$$
\varepsilon^{\prime}{ }_{r}=1+\frac{S_{r}}{2 S_{\varepsilon}} \cdot \frac{f_{r}-f_{\varepsilon}}{f_{r}}
$$

The sample had the form of a disc with a diameter of $11 \mathrm{~mm}$ and about $1.5 \mathrm{~mm}$ thickness. It was placed in the position of the maximum electric field of the cavity.

Dielectric loss angle tangent $\tan \delta$

The dielectric loss angle tangent $\tan \delta$ was calculated from the quality factor of the cavity with $Q_{\varepsilon}$ and without a sample $Q_{r}$

$$
\tan \delta=\frac{1}{4 \varepsilon_{r}} \frac{S_{r}}{S_{\varepsilon}}\left(\frac{1}{Q_{\varepsilon}}-\frac{1}{Q_{r}}\right)
$$

The measurement setup used several generators for the whole range: HP686A and G4-79 to 82 , frequency meters: H 532A; FS-54, cavity resonator (Figure 3).

The dielectric properties have been measured within the frequency range from $1 \mathrm{GHZ}$ to $10 \mathrm{GHz}$.

\section{Results and Discussion}

\subsection{Textural parameters of activated carbons and their influence on the vulcanization process of samples of materials}

The textural parameters, calculated on their basis following the methods, described in the experimental section, are listed in Table 2 .
In view of the fact that the applied active carbons have been used as reinforcing fillers, it has to be noted that not all textural parameters are of importance, but mostly the specific and the external surface areas and mainly the volume of the mesopores. This is due to the fact that the pore sizes that allow the penetration of the large elastomer macromolecules into the carbon particles are of significance. As far as the sizes of the micropores are concerned $<2.0 \mathrm{~nm}^{36}$ these are not accessible to the molecules of the elstomer. The same holds true also for the specific surface area of the micropores. Therefore, the parameters, associated with the micropores, will be considered only from the view point of comparison between the different samples of active carbons.

From the view point of the type of texture all the six studied samples of active carbons belong to the group of the micro-mesoporous materials.

The specific surface areas of the commercial active carbons are varying within a comparatively wider range (Table 2) as for example that of the trademark Norit is more than twice smaller than those of AC-L and 207C. This difference is especially strongly demonstrated in regard to the value of the external surface area, whereupon this value in the case of AG-K compared to those of $207 \mathrm{C}$ and AC-L is smaller respectively 2.7 and 3.1 times.

Substantial difference is displayed by the studied active carbons in the case of the vulcanization of NR based samples.

The vulcanization process is occurring and ending normally with the samples containing as fillers the active carbons: Norit, ART and AG-K, which we shall call conditionally "the first group", but it does not end in the case of the carbon fillers: AC-L, 207C and ACVM ("second group").

The volumes of the micropores and mesopores are varying within comparatively narrower limits in the studied active carbons. Thus the greatest observed difference in the volumes of the micropores - that between Norit and $207 \mathrm{C}$ is about 1.8 times. Analogously, in regard to the volumes of the mesopores, the difference between ART and AG-K on one side and AC-L on the other side (Table 2) is also 1.8 times.

The analysis of the carbon samples of the first group shows that the specific surface areas (with the exception of the ART sample) are comparatively low (Table 2), by analogy

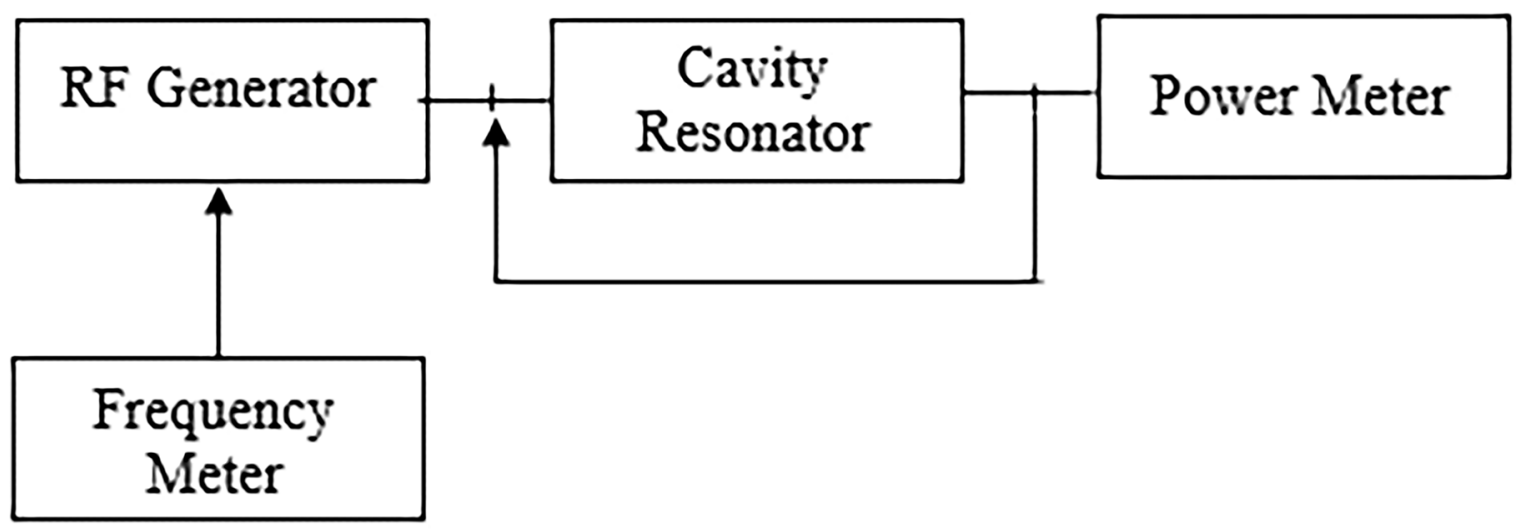

Figure 3. Scheme of the equipment for measuring the dielectric properties. 
Table 2. The main textural parameters of activated carbons used and their IEP values.

\begin{tabular}{|c|c|c|c|c|c|c|c|c|c|}
\hline Samples & $\begin{array}{l}\mathrm{A}_{\mathrm{BET}}, \\
\mathrm{m}^{2} / \mathrm{g}\end{array}$ & $\begin{array}{l}\mathrm{A}_{\mathrm{M}}, \\
\mathrm{m}^{2} / \mathrm{g}\end{array}$ & $\begin{array}{l}\mathrm{A}_{\mathrm{EXT}}, \\
\mathrm{m}^{2} / \mathrm{g}\end{array}$ & $\begin{array}{c}\mathrm{V}_{\mathrm{t}} \\
\mathrm{cm}^{3} / \mathrm{g}\end{array}$ & $\begin{array}{c}\mathrm{V}_{\mathrm{Ml}}, \\
\mathrm{cm}^{3} / \mathrm{g}\end{array}$ & $\begin{array}{l}\mathrm{V}_{\mathrm{MES}}, \\
\mathrm{cm}^{3} / \mathrm{g}\end{array}$ & $\begin{array}{c}\mathrm{D}_{\mathrm{AV}} \\
\mathrm{nm}\end{array}$ & IEP & $\mathrm{V}_{\mathrm{MES}} / \mathrm{A}_{\mathrm{EXT}}$ \\
\hline Norit & 518 & 400 & 118 & 0.33 & 0.21 & 0.12 & 2.5 & 7.2 & $10.2 .10^{-4}$ \\
\hline ART & 957 & 840 & 117 & 0.46 & 0.36 & 0.10 & 1.9 & 7.1 & $8.6 .10^{-4}$ \\
\hline AG-K & 652 & 569 & 83 & 0.33 & 0.23 & 0.10 & 2.0 & 6.4 & $12.10^{-4}$ \\
\hline AC-L & 1107 & 852 & 255 & 0.55 & 0.37 & 0.18 & 2.0 & 5.5 & $7.1 .10^{-4}$ \\
\hline $207 \mathrm{C}$ & 1111 & 890 & 222 & 0.55 & 0.39 & 0.16 & 2.0 & 5.3 & $7.2 .10^{-4}$ \\
\hline ACVM & 688 & 555 & 133 & 0.39 & 0.25 & 0.14 & 2.3 & 9.7 & $10.5 \cdot 10^{-4}$ \\
\hline
\end{tabular}

with it in the second group (with the exception of the ACVM samples having $\mathrm{A}_{\mathrm{BET}}=688 \mathrm{~m}^{2} / \mathrm{g}$ ) the remaining two samples are characterized by specific surface area $>1100 \mathrm{~m}^{2} / \mathrm{g}$.

Analogously, the external surfaces of the active carbons of the first group are lower than those of the second group of active carbons (Table 2).

There exists a possibility to explain this difference based on the isoelectric points (IEP) of the active carbons (Table 2). It is obvious that the values of IEP for the carbons of the first group are positioned at about 7 , while these values for the carbons of the second group are either under the value of the neutral point 7 (5.3 in the case of 207C sample and 5.5 for the AC-L sample) or it is 9.7 in the case of the ACVM sample. Therefore the availability of superficial oxygencontaining functional groups (SOG), whatever their nature is (acidic or basic) is restricting the utilization of active carbons as fillers in view of the negative influence of some of them with respect to the vulcanization process. We can recommend as appropriate fillers only those having IEP $\approx 7$.

Another important parameter, connected with the ability of the carbons to be acceptable in the function of reinforcing fillers, is the ratio between the volume of the mesopores and the external surface area. A logical prerequisite for it appears to be the fact that the external surface is easily accessible to the large molecules of the elastomer, while the internal surface of the mesopores (only that of the bigger ones) is not readily accessible to them.

It has been found out that the activated carbons exert serious influence upon the vulcanization process, which depends both on the chemistry of the surface of carbons (respectively on the IEPs), as well as on their textural parameters (most of all on the ratio $\mathrm{V}_{\mathrm{MES}} / \mathrm{A}_{\mathrm{EXT}}$ ). In order to accomplish a normal vulcanization process without any technological problems it is necessary that the ratio $\mathrm{V}_{\mathrm{MES}} /$ $A_{\text {EXT }}$ should be within the limits (8.5-12.0)10-4 and at the same time the IEP should be close to 7 . It may be concluded that only the activated carbons ART, AG-K and Norit are suitable for application as reinforcing fillers. This is why we used them in our further investigations.

\subsection{Microwave properties}

Figure 4 represents frequency dependence of reflection coefficients $|\Gamma|$ of composites containing ART, AG-K and

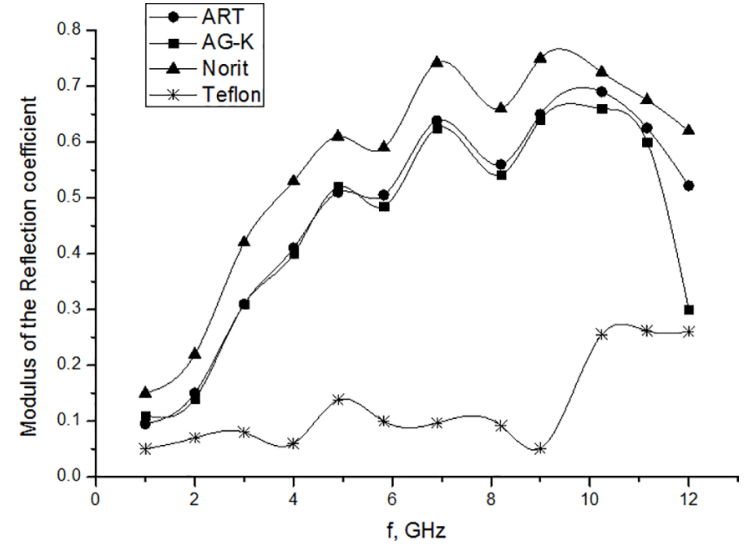

Figure 4. Frequency dependence of reflection coefficients $|\Gamma|$ of composites containing ART, AG-K and Norit fillers.

Norit fillers. It is seen that at the frequency range from 1 $\mathrm{GHz}$ to $5 \mathrm{GHz}$ the coefficient of reflection is growing up monotonously for all the materials, while for the range from $5 \mathrm{GHz}$ to $9 \mathrm{GHz}$ a resonance character is observed. The three studied materials manifest high values of the coefficient of reflection within the frequency range from $5 \mathrm{GHz}$ to 11 $\mathrm{GHz}$. At frequencies higher than $10 \mathrm{GHz}$ a monotonous decrease in the coefficient of reflection is observed, which is more strongly expressed in the case of the material AG-K. For confirming the correctness of the measurements done for each frequency a standard Teflon probe (PTFE load of thickness $1 \mathrm{~mm}$ ) has been measured.

The coefficients of attenuation of composites containing ART, AG-K and Norit fillers depending on frequency are shown in Figure 5.

It is seen that the attenuation coefficient is sensitive towards changes in frequency. Within the range from $1 \mathrm{GHz}$ to $6 \mathrm{GHz}$ the values of the attenuation coefficient are growing up with increase the frequency. Within the range from 5 $\mathrm{GHz}$ to $12 \mathrm{GHz}$ a strongly expressed resonance character is observed. The maximal values are observed at $6 \mathrm{GHz}$, $8 \mathrm{GHz}$ and $11 \mathrm{GHz}$, while the minimal ones are at $7 \mathrm{GHz}$ and at $9 \mathrm{GHz}-10 \mathrm{GHz}$. The highest values of the attenuation coefficient within the studied range are displayed by the active carbon Norit - about $22 \mathrm{~dB} / \mathrm{cm}$. The composite containing the AG-K displays an interesting behavior -at frequencies 11-12 GHz sharply raises the attenuation coefficient, which reaches a value of $27 \mathrm{~dB} / \mathrm{cm}$. 


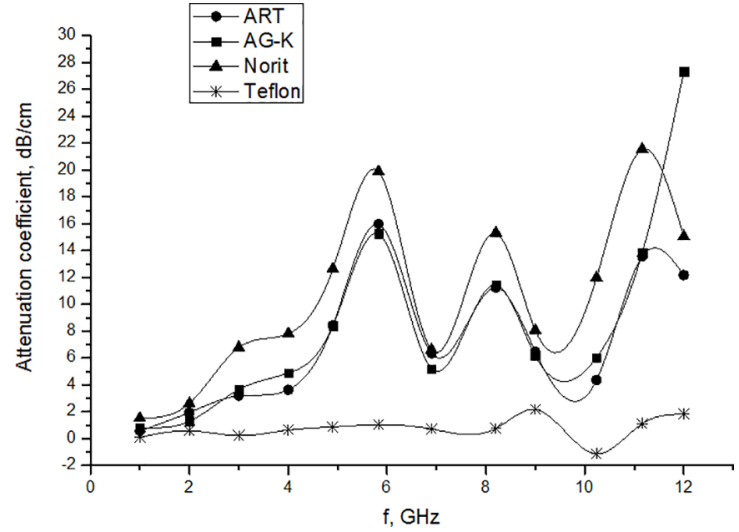

Figure 5. Frequency dependence of attenuation coefficient $\alpha, \mathrm{dB} /$ $\mathrm{cm}$ of composites containing ART, AG-K and Norit fillers.

\subsection{Total shielding effectiveness}

Figure 6 represents the frequency dependence of total shielding effectiveness, $S E, \mathrm{~dB}$ of composites containing ART, AG-K and Norit fillers. It is seen that the sample Norit has larger values of the total shielding effectiveness (SE) with about $2 \mathrm{~dB}$ by comparison with another two samples. Within the frequency range from $1 \mathrm{GHz}$ to $11 \mathrm{GHz}$ the total shielding effectiveness for all three materials (ART, AG-K and Norit) has identical behavior, whereas for frequencies up to $6 \mathrm{GHz}$ it is increasing with the frequency. Further within the range from $7 \mathrm{GHz}$ to $10 \mathrm{GHz}$ low sensitivity is observed with respect to changes in the frequency.

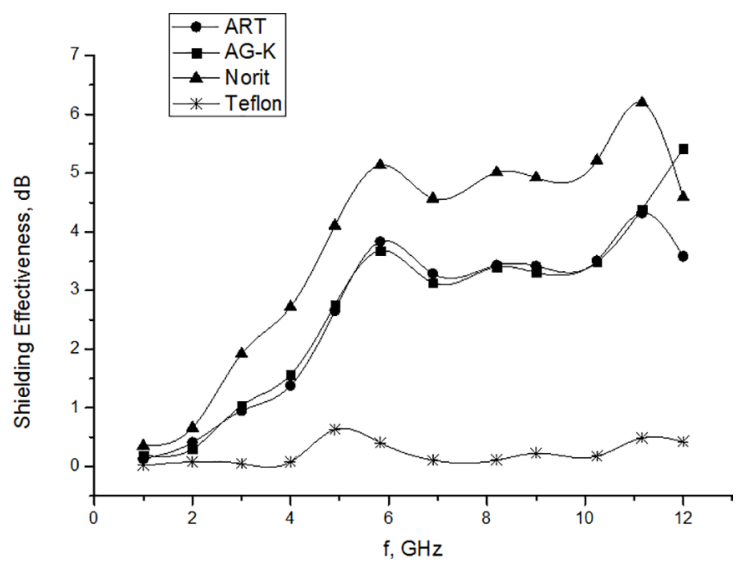

Figure 6. Frequency dependence of total shielding effectiveness, $\mathrm{SE}, \mathrm{dB}$ of composites containing ART, AG-K and Norit fillers.

Figures 7-8 illustrates the results on the reflective shielding effectiveness $\left(S E_{R}\right)$ and absorptive shielding effectiveness $\left(S E_{A}\right)$.

From the plots in Figure 8 one can determine that the highest reflective shielding effectiveness comes as a consequence of the reflection from the surface of the sample - the tested sample is Norit. For the other two tested samples

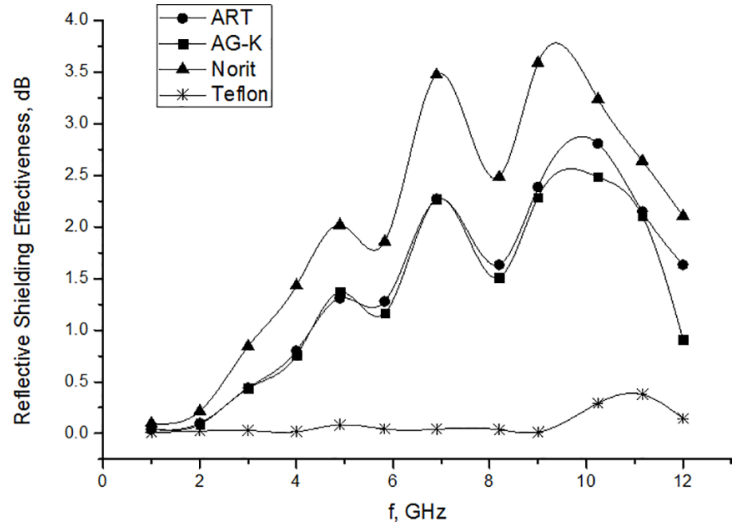

Figure 7. Frequency dependence of reflective shielding effectiveness, $\mathrm{SE}_{\mathrm{R}}, \mathrm{dB}$ of composites containing ART, AG-K and Norit fillers.

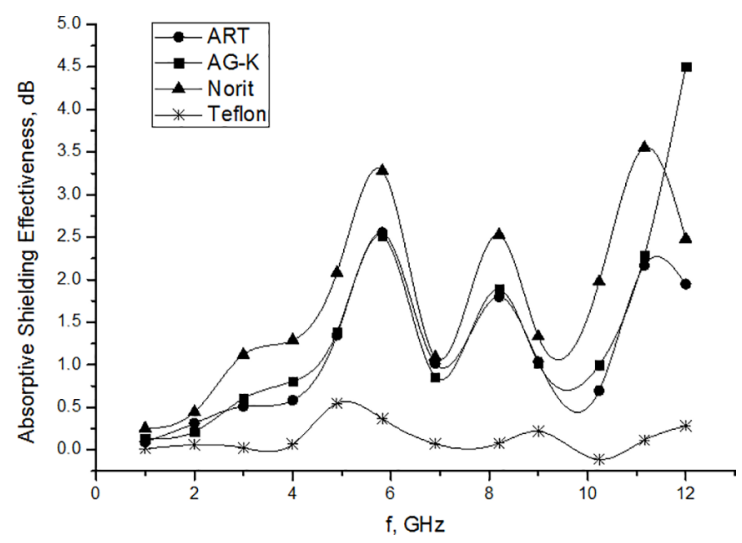

Figure 8. Frequency dependence of absorptive shielding effectiveness, $\mathrm{SE}_{\mathrm{A}}, \mathrm{dB}$ of composites containing ART, AG-K and Norit fillers.

the values of $S E_{R}$ are very close to each other within the entire frequency range.

On Figure 8 it is seen that within the range from 1 $\mathrm{GHz}$ up to $11 \mathrm{GHz}$ the Norit sample displays the greatest absorption. At frequencies higher than $11 \mathrm{GHz}$ the AG-K material possesses higher values of $S E_{A}$, showing a different behavior in regard to the other two materials and determining the behavior of the total shielding effectiveness.

For all studied materials the reflective and absorptive shielding effectiveness manifest resonance behavior at frequencies from $6 \mathrm{GHz}$ to $12 \mathrm{GHz}$, whereupon at frequency $6 \mathrm{GHz}$ the $\mathrm{SE}_{\mathrm{A}}$ is prevailing, while within the range from 7 $\mathrm{GHz}$ to $11 \mathrm{GHz}$, the reflecting component $\left(\mathrm{SE}_{\mathrm{R}}\right)$ is prevailing in the total shielding effectiveness.

The study of the electromagnetic properties of an ensemble of filler particles embedded in a polymer matrix requires the determination of not only the intrinsic electromagnetic properties of the individual filler particles but also the type and strength of interparticle interactions, e.g., long-range dipoledipole interactions, clustering, and matrix-particle interactions, such as multicontact chain adsorption to the surface of the filler. It has been well established that spatial 
inhomogeneities, i.e., clusters of filler particles, give rise to polarization phenomena and therefore to a frequency dependence of the effective permittivity ${ }^{37}$

Homogeneous and heterogeneous media analyzed within an effective medium approach are described by two material parameters: the complex (relative) permittivity e $\varepsilon=\varepsilon$ ' - j $\varepsilon$ " and the magnetic permeability (relative) $\mu=\mu^{\prime}-\mathrm{j} \mu$ '. The terms $\varepsilon^{\prime}$ (and $\mu^{\prime}$ ) are associated with energy storage and $\varepsilon "$ (and $\mu$ ") are associated with dielectric loss or energy dissipation within a material resulting from conduction, resonance, and relaxation mechanisms. The loss tangent of the dielectric material is $\tan \delta=\varepsilon " / \varepsilon$, where $\delta$ is the dielectric loss angle of the material. Energy loss in a material illuminated by electromagnetic waves comes about through damping forces acting on polarized atoms and molecules and through the finite conductivity of a material.

Through equations available in the literature ${ }^{8}$, we can see that the combination of the magnetic permeability and the permittivity of the absorbing composite satisfying the impedance matching condition is the key to producing a high-performance microwave absorber. Specifically, for a single layer of absorber backed by a PEC [perfect electric conductor] the reflection loss and the attenuation constant are dependent on complex magnetic permeability, permittivity, and frequency. If we consider diamagnetic carbonaceous materials, microwave absorbers is due to dielectric losses.

In the case of a dielectric absorbent, assuming that $\mu=1-\mathrm{j} 0$, the maximum reflection loss and the attenuation coefficient depend on real and imaginary part of permittivity, dielectric loss angle tangents at a given frequency ${ }^{8}$. This is why to explain the effect observed we investigated the dielectric properties of the composites studied.

Figures 9 and 10 illustrate the dielectric parameters of the tested materials within a wide frequency band from 1 $\mathrm{GHz}$ to $10 \mathrm{GHz}$. For all materials one can observe increase in the real part of the relative dielectric permittivity $\left(\varepsilon_{r}\right)$ upon increasing the frequency up to $3 \mathrm{GHz}$ (Fig. 9), while for the frequency range from $5 \mathrm{GHz}$ to $10 \mathrm{GHz}$ one can observe weak influence of the frequency. Within the studied range the material ART possesses higher values of $\varepsilon_{r}$ in comparison to the other materials.

Figure 10 depicts in a logarithmic scale the results from the measurements of $\tan \delta_{\varepsilon}$. It is seen that this parameter is much more sensitive to changes in the frequency, and also to the quantity of the fillers in the tested samples themselves. Within the frequency range from $1 \mathrm{GHz}$ to $5 \mathrm{GHz}$ all three materials have relatively high values of $\tan \delta$, and it is probably for this reason that the values of the shielding effectiveness are smaller in this range. Within the frequency range from $5 \mathrm{GHz}$ to $10 \mathrm{GHz}$ the ART material displays higher values of $\tan \delta_{\varepsilon}$.

The results of these measurements explain the observed microwave properties of the composites. It is obvious that the dielectric permittivity and the dielectric loss of the composite

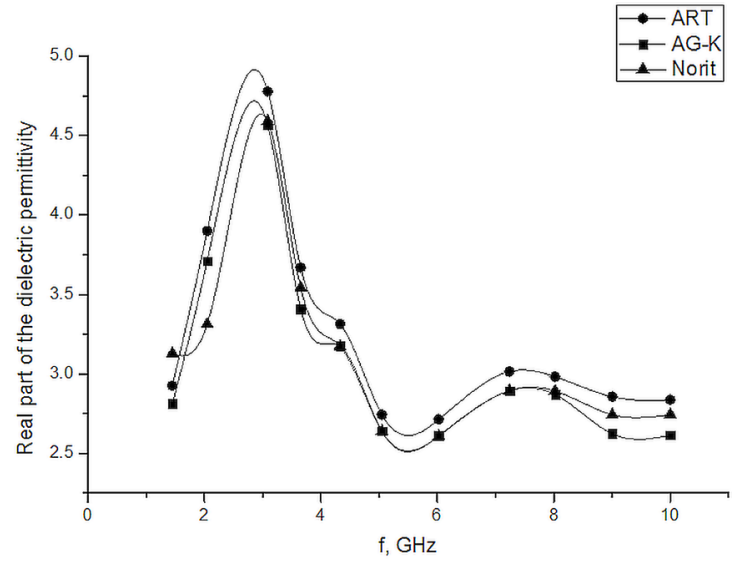

Figure 9. Frequency dependence of the real part of the dielectric permittivity for the studied materials.

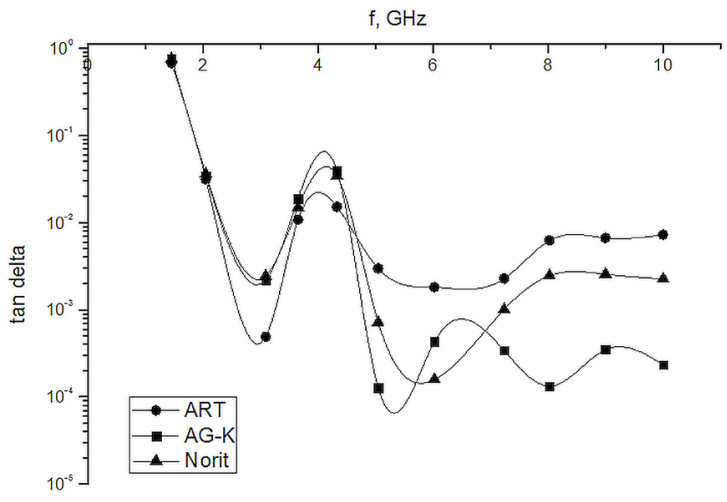

Figure 10. Frequency dependence of the dielectric losses $\tan \delta_{\varepsilon}$ for the studied materials.

medium depends on the intrinsic permittivity of the phases, their volume fraction, their shape and size, their geometrical arrangement associated with the material mixture and their textural characteristics. The textural characteristics of the activated carbons used as functional fillers are different (Table 2). This is the reason for their different effect on the real part of dielectric permittivity and dielectric loss angle tangent as well as on the microwave properties of the composites. It was found that the highest value of the total shielding effectiveness possess the composites containing the activated carbon Norit. It has the lowest values of specific surface area, area and volume of micropores and the highest values of external surface area, volume of mesopores and average pore diameter. With gradually increasing the values of the indices in the first group and gradually decreasing the values of the indices in the second group, the value of total shielding effectiveness in the row Norit, AG-K and ART decreases. It is obvious that these indices have influence on the rubber matrix-filler particle interactions, such as multicontact chain adsorption to the surface of the filler. The spatial inhomogeneities formed give rise to polarization phenomena and to a frequency dependence of the dielectric 
permittivity ${ }^{37}$. It may be considered as a prove for the effect of activated carbons textural characteristics on the dielectric and microwave properties of containing them composites.

\section{Conclusions}

Six types of activated carbon different in their adsorptiontextural parameters have been studied as functional fillers of composite materials based on natural rubber. These types of active carbon are Norit, AG-K, ART, AC-L, 207C and ACVM.

It has been found out that the activated carbons exert serious influence upon the vulcanization process, which depends both on the chemistry of the surface of carbons (respectively on the IEPs), as well as on their textural parameters (most of all on the ratio $\mathrm{V}_{\mathrm{MES}} / \mathrm{A}_{\mathrm{EXT}}$ ). In order to accomplish a normal vulcanization process without any technological problems it is necessary that the ratio $\mathrm{V}_{\mathrm{MES}}$ ' $\mathrm{A}_{\mathrm{EXT}}$ should be within the limits (8.5-12.0)10 $0^{-4}$ and at the same time the IEP should be close to 7 .

It has been observed that the composite containing activated carbon Norit possesses the highest value of the total shielding effectiveness in comparison with the composites, containing the carbons AG-K and ART. It has the lowest values of specific surface area, area and volume of micropores and the highest values of external surface area, volume of mesopores and average pore diameter. With gradually increasing the values of the indices in the first group and gradually decreasing the values of the indices in the second group, the value of total shielding effectiveness in the row Norit, AG-K and ART decreases. It is obvious that these indices have influence on the rubber matrix-filler particle interactions, such as multicontact chain adsorption to the surface of the filler. It is obvious also that the textural characteristics of the studied active carbons exert influence both on the dielectric, as well as on the microwave properties of the studied composites.

Some of the studied active carbons (Norit, ART and AG$\mathrm{K}$ ), answering the requirement for appropriate values of the IEPs and of the textural parameters can be used as fillers in elastomeric composites designed for microwave application.

\section{Acknowledgements}

The authors would like to acknowledge the support of King Khalid University for this research through a grant RCAMS/KKU/003-16 under the Research Center for Advanced Materials Science at King Khalid University, Saudi Arabia and the University of Chemical Technology and Metallurgy, Sofia, Bulgaria.

\section{References}

1. Al-Hartomy OA, Al-Ghamdi AA, Al-Salamy F, Dishovsky N, Shtarkova R, Slavcheva D, et al. Effect of Matrix Chemical Nature on the Properties of Composites for Microwave
Absorbers. Polymer-Plastics Technology and Engineering. 2013;52(11):1113-1121.

2. Al-Hartomy OA, Al-Ghamdi AA, Al-Salamy F, Dishovsky N, Slavcheva D. Iliev V, et al. Dielectric and Microwave Properties of Fullerenes Containing Natural Rubber-based Nanocomposites. Fullerenes, Nanotubes, and Carbon Nanostructures. 2014;22(4):332-345.

3. Lederer PG. An Introduction to Radar Absorbent Materials (RAM). Malvern: Royal Signals and Radar Establishment; 1986.

4. Gaylor K. Radar Absorbing Materials-Mechanisms and Materials. Maribyrnong: DSTO Materials Research Laboratory; 1989.

5. Knott EF, Shaeffer JF, Tuley MT. Radar Cross Section. $2^{\text {nd }}$ rev. ed. Raleigh: SciTech Publishing; 2004.

6. Vinoy KJ, Jha RM. Radar Absorbing Materials-From Theory to Design and Characterization. Boston: Kluwer Academic Publishers; 1996.

7. Emerson W. Electromagnetic wave absorbers and anechoic chambers through the years. IEEE Transactions on Antennas and Propagation. 1973;21(4):484-490.

8. Qin F, Brosseau C. A review and analysis of microwave absorption in polymer composites filled with carbonaceous particles. Journal of Applied Physics. 2012;111(6):061301.

9. Dishovsky N. Rubber based composites with active behavior to microwaves. Journal of the University of Chemical Technology and Metallurgy. 2009;44(2):115-122.

10. Shtarkova R, Dishovsky N. Elastomer-based Microwave Absorbing Materials. Journal of Elastomer \& Plastics. 2009;41(2):163-174.

11. Dishovsky N, Grigorova M. On the correlation between electromagnetic waves absorption and electrical conductivity of carbon black filled polyethylenes. Materials Research Bulletin. 2000;35(3):403-409.

12. El-Tantawy F, Dishovsky N. Novel V-shaped negative temperature coefficient of conductivity thermistors and electromagnetic interference shielding effectiveness from butyl rubber-loaded boron carbide ceramic composites. Journal of Applied Polymer Science. 2004;91(5):2756-2770.

13. Attharangsan $\mathrm{S}$, Ismail $\mathrm{H}$, Bakar MA, Ismail J. Carbon Black (CB)/Rice Husk Powder (RHP) Hybrid Filler-Filled Natural Rubber Composites: Effect of CB/RHP Ratio on Property of the Composites. Polymer-Plastics Technology and Engineering. 2012;51(7):655-662.

14. Ling Q, Sun J, Zhao Q, Zhou Q. Effects of Carbon Black Content on Microwave Absorbing and Mechanical Properties of Linear Low Density Polyethylene/Ethylene-Octene Copolymer/ Calcium Carbonate Composites. Polymer-Plastics Technology and Engineering. 2011;50(1):89-94.

15. Das TK, Prusty S. Review on Conducting Polymers and Their Applications. Polymer-Plastics Technology and Engineering. 2012;51(14):1487-1500.

16. Chandran SA, Narayanankutty SK, Mohanan P. Microwave Characteristics of Polyaniline Based Short Fiber Reinforced Chloroprene Rubber Composites. Polymer-Plastics Technology and Engineering. 2011;50(5):453-458. 
17. Bai X, Zhai YH, Zhang Y. Green Approach To Prepare GrapheneBased Composites with High Microwave Absorption Capacity. Journal of Physical Chemistry C. 2011;115(23):11673-11677.

18. Fang JJ, Li SF, Zha WK, Cong HY, Chen JF, Chen ZZ. Microwave Absorbing Properties of Nickel-coated Graphene. Journal of Inorganic Materials. 2011;26(5):467-471.

19. Zhang HB, Yan Q, Zheng WG, He ZX, Yu ZZ. Tough Graphene-Polymer Microcellular Foams for Electromagnetic Interference Shielding. ACS Applied Materials \& Interfaces. 2011;3(3):918-924.

20. Kienle H, Bäder E. Activkohle und ihre industrielle Anwendung. Stuttgart: Ferdinand EnkeVerlag; 1980.

21. Dubinin MM, Astakhov VA. Description of Adsorption Equilibria of Vapors on Zeolites over Wide Ranges of Temperature and Pressure. In: Flanigen EM, Sand LB, eds. Molecular Sieve Zeolites II. Washington: American Chemical Society; 1971. p. 69-85.

22. Sing KSW. In: Everett DH, Ottewill RH, eds. Surface area determination: proceedings of the International Symposium on Surface Area Determination; 1969 Jul 16-18; Bristol, U.K. London: Butterworths; 1970. p. 15.

23. Noh JS, Schwarz JA. Effect of $\mathrm{HNO}_{3}$ treatment on the surface acidity of activated carbons. Carbon. 1990;28(5):675-682.

24. Mark JE, Erman B, Eirich FR, eds. The Science and Technology of Rubber. $3^{\text {rd }}$ ed. Amsterdam: Elsevier; 2005.

25. Jana PB, Mallick AK, De SK. Effects of sample thickness and fiber aspect ratio on EMI shielding effectiveness of carbon fiber filled polychloroprene composites in the $\mathrm{x}$-band frequency range. IEEE Transactions on Electromagnetic Compatibility. 1992;34(4):478-481.

26. Paul CR. Introduction to Electromagnetic Compatibility. $2^{\text {nd }}$ ed. Hoboken: Wiley; 2006.

27. Ott HW. Electromagnetic Compatibility Engineering. Hoboken; Wiley; 2009.
28. Villacorta Hernandez B. Effect of Graphitic Carbon Nanomodifiers on the Electromagnetic Shielding Effectiveness of Linear Low Density Polyethylene Nanocomposites. [Dissertation]. Clemson: The Graduate School of Clemson University; 2013.

29. Sadasivuni KK, Ponnamma D, Kim J, Thomas S, eds. GrapheneBased Polymer Nanocomposites in Electronics. Cham: Springer International Publishing; 2015.

30. Park SH, Theilmann PT, Asbeck PM, Bandaru PR. Enhanced Electromagnetic Interference Shielding Through the Use of Functionalized Carbon-Nanotube-Reactive Polymer Composites. IEEE Transactions on Nanotechnology. 2010;9(4):464-469.

31. Hong YK, Lee CY, Jeong CK, Lee DE, Kim K, Joo J. Method and apparatus to measure electromagnetic interference shielding efficiency and its shielding characteristics in broadband frequency ranges. Review of Scientific Instruments. 2003;74(2):1098.

32. Więckowski TW, Janukiewicz JM. Methods for Evaluating the Shielding Effectiveness of Textiles. Fiber \& Textiles in Eastern Europe. 2006;59(5):18-22.

33. Chen LF, Ong CK, Neo CP, Varadan VV, Varadan VK. Microwave Electronics Measurement and Material Characterization. Chichester: Wiley; 2004.

34. High-Directivity Coaxial Directional Couplers and Reflectometers. Hewlett Packard Journal. 1955;7(2).

35. A New Frequency Counter Plug-In Unit for Direct Frequency Measurments to 510 MC. Hewlett Packard Journal. 1961;12(5).

36. Recommendations for the characterization of porous solids IUPAC. Pure and Applied Chemistry. 1994;66(8):1739-1758.

37. Brosseau C. Mesostructure and network properties of filled polymers: A study of linear low-density polyethylene carbon black composites. In: Brosseau C, ed. Prospects in Filled Polymers Engineering: Mesostructure, Elasticity Network, and Macroscopic Properties. Trivandrum: Research Signpost; 2008. p. 177-227. 